\title{
Burnout and well-being in young doctors in Hong Kong: a territory-wide cross-sectional survey
}

\author{
Kenny YH Kwan *, Loretta WY Chan, PW Cheng, Gilberto KK Leung, CS Lau; for the Young Fellows \\ Chapter of the Hong Kong Academy of Medicine
}

This article was published on 5 Oct 2021 at www.hkmj.org.

\section{A B S T R A C T}

Introduction: This territory-wide study evaluated the level of burnout and health status among young doctors in Hong Kong.

Methods: All young doctors in Hong Kong, defined as residents-in-training or doctors within 10 years of their specialist registration, were invited to participate in an online cross-sectional survey. This survey used standardised questionnaires including the Copenhagen Burnout Inventory (CBI) for burnout, Patient Health Questionnaire-9 for depression, and general health questionnaires.

Results: In total, 514 doctors completed the survey; 284 were doctors within 10 years of their specialist registration, while 230 were residents-in-training. There were 277 women (54\%); among all respondents, the mean age was $33.7 \pm 6.1$ years. Using a CBI subscale cut-off score of $\geq 50$ (moderate and higher), $72.6 \%$ $(\mathrm{n}=373)$ of respondents reported personal burnout; $70.6 \%(n=363)$ of respondents reported work-related burnout; and $55.4 \%(n=285)$ of respondents reported client-related burnout. Furthermore, $24 \%(n=125)$ of respondents were "somewhat dissatisfied" with their present job position; $4 \%(n=19)$ of respondents were "very dissatisfied" with their present job position. The prevalence of depression among respondents was $21 \%(n=110)$.
Conclusions: In this territory-wide cross-sectional survey of young doctors in Hong Kong, a high prevalence of burnout was identified among young doctors; respondents exhibited a considerable level of depression and substantial dissatisfaction with their current positions. Strategies to address these problems must be formulated to ensure the future well-being of the medical and dental workforce in Hong Kong.

\section{Hong Kong Med J 2021;27:330-7 https://doi.org/10.12809/hkmj219610}

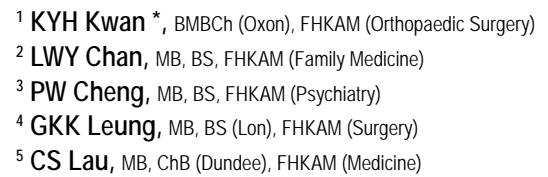

Department of Orthopaedics and Traumatology, The University of Hong Kong, Hong Kong

Family Medicine, Private Practice

${ }^{3}$ Department of Psychiatry, The University of Hong Kong, Hong Kong

${ }^{4}$ Department of Surgery, The University of Hong Kong, Hong Kong

Department of Medicine, The University of Hong Kong, Hong Kong

* Corresponding author: kyhkwan@hku.hk

New knowledge added by this study

- There is a high prevalence of burnout among young doctors in Hong Kong; of 514 survey respondents, $72.6 \%$ reported personal burnout, 70.6\% reported work-related burnout, and 55.4\% reported client-related burnout.

- The prevalence of depression among young doctors (21\% in this study) was considerably higher than among the general population in Hong Kong ( $8.4 \%$ in a previous study).

- Overall, $28 \%$ of respondents were either "somewhat dissatisfied" or "very dissatisfied" with their present job position.

Implications for clinical practice or policy

- Changes to the number of working hours per week and extent of clinical responsibilities may help to reduce burnout among junior doctors.

- Efforts to promote stronger social networks among junior doctors and their communities may reduce the risk of burnout, although further studies are needed to validate this hypothesis.

- Although the respondents did not indicate reliance on substance or alcohol abuse, there is a need for greater workplace emphasis on positive health and lifestyle behaviours to reduce the risk of burnout among junior doctors.

\section{Introduction}

Burnout among doctors is increasingly recognised as a serious threat to medical and dental practice across all specialties; its prevalence is increasing worldwide. $^{1}$ Burnout is a spectrum of clinical syndromes that were first categorised into three dimensions by Maslach as emotional exhaustion, depersonalisation, and a low sense of personal accomplishment. $^{2}$ Subsequently, it was added to the International Classification of Diseases as a 
syndrome that results from poorly managed chronic workplace stress. ${ }^{3}$

Burnout among doctors can lead to decreased effectiveness and shortening of professional lifespan. ${ }^{4}$ Burnout exacerbates negative emotions, thereby impeding cognitive performance; it may result in biased decision making. Hence, the well-being of doctors is important for maintaining manpower, quality of care, and equity of care delivery. Multiple studies in different countries have shown that the incidence of burnout among doctors is rising. In the US, a Medscape nationwide survey showed that $59 \%$ of emergency medicine doctors experienced burnout symptoms, and the incidence had increased steadily over time. ${ }^{1}$ In Australia, the National Mental Health Survey found that the level of very high psychological distress was significantly greater in doctors $(3.4 \%)$ than in the general population $(2.6 \%)$ or other professionals $(0.7 \%) .^{5}$ A cross-sectional online survey in the United Kingdom also revealed a high rate of mental health disorders among junior doctors and medical students. ${ }^{6}$

To our knowledge, studies regarding wellbeing and burnout among doctors in Asia are limited. Gan et $\mathrm{al}^{7}$ performed a cross-sectional study of general practitioners in Hubei, China; they found a combined prevalence of $2.46 \%$ across all three dimensions of emotional exhaustion, depersonalisation, and personal accomplishment. However, that study only included doctors within a single specialty in one province. Huang et $\mathrm{al}^{8}$ found the prevalences of personal burnout and clientrelated burnout were $44.0 \%$ and $14.8 \%$, respectively, among residents in Taiwan; however, they used a non-standardised questionnaire. In Hong Kong, a previous cross-sectional survey showed that $31.4 \%$ of respondents among doctors in the public sector had a high rate of burnout, but the sampling criteria were random and non-specific; moreover, that study did not include a substantial proportion of doctors who worked in the private sector. ${ }^{9}$ Another survey also suggested that burnout was prevalent among doctors in Hong Kong, but it only included graduates from one medical school in Hong Kong. ${ }^{10}$

Hence, this study aimed to evaluate the prevalence of burnout in the Hong Kong medical and dental workforce by administering standardised questionnaires to a broad population of residentsin-training and doctors within 10 years of their specialist registration. The study also explored wellbeing among doctors in terms of job satisfaction, depression, lifestyle behaviours, and factors associated with these states.

\section{Methods}

\section{Survey and study population}

In this study, all doctors within 10 years of their

\section{香港年青醫生工作過度勞累和身心健康的全港 橫斷面調查 \\ 關日康、陳穎欣、鄭柏榮、梁嘉傑、劉澤星、香港醫學專科 學院年青院士分會 \\ 引言：這項全港研究評估香港年青醫生的工作過度勞累和健康狀況。}

方法: 香港所有年青醫生（正接受專科培訓的學員或近十年間完成專 科培訓的年青院士）獲邀參與線上橫斷面調查。這項調查使用標準化 問卷, 包括評估工作過度勞累的哥本哈根疲勞量表（CBI）、評估抑 鬱症的病人健康狀況問卷-9和一般健康問卷

結果：514名受訪者中, 284名是於近十年間完成專科培訓的年青院 士 , 其餘230名則為正接受專科培訓的學員。受訪者中2 77 名為女性

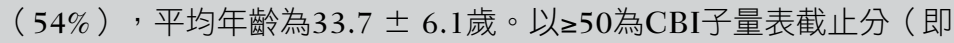
中等和更高程度），72.6\%（ $\mathrm{n}=373 ）$ 受訪者出現過度勞累； $70.6 \%$ $(n=363)$ 受訪者出現與工作相關的過度勞累； $55.4 \% （ n=285)$ 受訪者的過度勞累與病人相關。此外, 分別有 $24 \%(n=125)$ 及 $4 \%(n=19)$ 受訪者對現時的工作崗位感到「有些不滿」和「十分不 滿」。21\% ( $n=110)$ 受訪者出現抑鬱。

結論 : 這項全港年青醫生橫斷面調查顯示, 相當高比例的年青醫生出 現過度勞累、抑鬱和對當前工作崗位嚴重不滿。必須制定解決這些問 題的策略，確保香港醫護人員和牙醫的身心健康。

specialist registration registered with the Hong Kong Academy of Medicine, as well as residentsin-training registered with one of the Academy's 15 constituent Colleges, were invited to complete a voluntary cross-sectional survey between February 2019 and June 2019. The cut-off of 10 years was selected because the Hong Kong Academy of Medicine considers doctors within 10 years of their specialist registration to be "young Fellows". The survey consisted of self-reported demographic data, year of entry into medical school, and current professional details. Burnout was assessed using the validated Copenhagen Burnout Inventory (CBI). ${ }^{11}$ Depression was assessed using the Patient Health Questionnaire-9 (PHQ-9). ${ }^{12}$ Lifestyle factors were assessed with reference to the respondents' drinking habits, sleep patterns, and levels of both exercise and activities. Items concerning job satisfaction and lifestyle behaviours were adapted from existing doctor questionnaires and health surveys. ${ }^{13,14}$

An online survey was developed in-house by the Hong Kong Jockey Club Innovative Learning Centre for Medicine of the Hong Kong Academy of Medicine, then administered electronically. The invitations to participate were sent via e-mail; two separate reminder emails were sent after the initial invitation. As an incentive, respondents were offered coffee or food coupons after completion of the survey. The study protocol was approved by the Institutional Review Board of the University of Hong 
Kong/Hospital Authority Hong Kong West Cluster (Ref No: UW 19-062).

\section{Sample size calculation}

PASS 2000 (NCSS, LLC., Kaysville [UT], US; www. ncss.com) power analysis software was used for sample size calculation. The prevalence of personal burnout among young doctors in Hong Kong was assumed to be similar to the prevalence of personal burnout among residents in Taiwan $(44.0 \%)^{8}$; thus, to achieve a 95\% confidence interval (CI) with a precision of $4.5 \%, 458$ participants were required. Our final sample of 514 doctors was sufficient to achieve the desired statistical power.

\section{Specific instruments}

\section{Copenhagen Burnout Inventory}

This instrument consists of three scales that measure personal burnout, work-related burnout, and clientrelated burnout; the scales can be applied to workers in all industries and cultures. Personal burnout measures the degree of fatigue experienced by the respondent, irrespective of work experience or occupational status. Work-related burnout measures the degree of fatigue related to work; it explores how the respondent's perception of work contributes to fatigue. Client-related burnout is the perceived degree of fatigue related to work with clients. The burnout level is calculated as a mean score; therefore, each scale has a value between 0 and 100. A score of $\geq 50$ indicates a high degree of burnout. ${ }^{15-18}$

\section{Patient Health Questionnaire-9}

The PHQ-9 is a depression assessment tool, which scores each of the nine Diagnostic and Statistical Manual of Mental Disorders IV criteria for depression on a scale ranging from "0" (not at all) to "3" (nearly every day). A PHQ-9 score $>9$ has a reported sensitivity of $88 \%$ and specificity of $88 \%$ for major depression. ${ }^{19}$

\section{Statistical analysis}

The prevalence of burnout is shown using point estimates and 95\% CIs. Descriptive statistics were presented concerning demographic characteristics and lifestyle behaviours. Bivariate logistic models were used to describe the distinct relationships of suicide, depression, and burnout with demographic, educational, and professional characteristics. The data were analysed using SPSS software (Windows version 26.0; IBM Corp, Armonk [NY], US). Statistical significance was set at $\mathrm{P}<0.05$.

\section{Results}

\section{Participant demographics}

There were 746 total respondents; of these, $232 \mathrm{did}$ not complete the entire survey and were excluded from the analysis. Of the included 514 respondents, 284 were doctors within 10 years of their specialist registration, while 230 were residents-in-training. The total number of doctors within 10 years of their specialist registration invited to participate in the survey was 2879; thus, the response rate was estimated as $9.9 \%$. However, it was not possible to calculate the response rate for residents-in-training. The respondents included 277 women (54\%); the mean age among all respondents was $33.7 \pm 6.1$ years. The respondents' demographic data are summarised in Table 1; their current professional statuses are summarised in Table 2.

\section{Professional satisfaction}

Overall, 24\% ( $n=125)$ of respondents were "somewhat dissatisfied" with their present job position, while $4 \%(n=19)$ of respondents were "very dissatisfied" with their present job position. Furthermore, 15\% $(n=76)$ of respondents were "somewhat dissatisfied" with being a medical doctor, whereas $2 \%(n=10)$ of respondents were "very dissatisfied" with being a medical doctor. Finally, 3\% $(n=14)$ of respondents indicated they planned to stop practising medicine in the next 12 months, with stress or burnout (86\%) cited as the most common reason for such plans.

TABLE I. Respondent demographics $(n=5 \mid 4)^{*}$

\begin{tabular}{|c|c|}
\hline \multicolumn{2}{|l|}{ Gender } \\
\hline Female & $277(53.9 \%)$ \\
\hline Male & $237(46.1 \%)$ \\
\hline Age, y & $33.7 \pm 6.1$ \\
\hline \multicolumn{2}{|l|}{ Marital status } \\
\hline Married/common-law & $272(52.9 \%)$ \\
\hline Single/separated/divorced & $242(47.1 \%)$ \\
\hline Have children & $173(33.7 \%)$ \\
\hline \multicolumn{2}{|l|}{ Completed education } \\
\hline \multicolumn{2}{|l|}{ Final year of secondary school } \\
\hline Hong Kong (EDB school) ${ }^{\dagger}$ & $440(85.6 \%)$ \\
\hline Hong Kong (independent school) ${ }^{\dagger}$ & $22(4.3 \%)$ \\
\hline Outside of Hong Kong & $52(10.1 \%)$ \\
\hline
\end{tabular}

First university degree (no undergraduate $468(91.1 \%)$ degree prior to medical school)

Medical school followed a PBL curriculum (HKU [MB, BS] / $267(51.9 \%)$ CUHK [MB, ChB] / HKU [BDS])

Abbreviations: CUHK = The Chinese University of Hong Kong; $\mathrm{EDB}=$ Education Bureau of the Hong Kong SAR Government; $\mathrm{HKU}=$ The University of Hong Kong; $\mathrm{PBL}=$ problem-based learning

Data are shown as No. (\%) or mean \pm standard deviation Most public and private secondary schools in Hong Kong conform to the standards of the EDB; some private schools are independent of the EDB 
TABLE 2. Current professional status $(n=5 \mid 4)^{*}$

\begin{tabular}{|c|c|}
\hline \multicolumn{2}{|l|}{ Current specialty } \\
\hline Anaesthesiology & $30(5.8 \%)$ \\
\hline Community Medicine & $11(2.1 \%)$ \\
\hline Dental Surgery & $28(5.4 \%)$ \\
\hline Emergency Medicine & $28(5.4 \%)$ \\
\hline Family Medicine/General Practice & $99(19.3 \%)$ \\
\hline Internal Medicine & $29(5.6 \%)$ \\
\hline Obstetrics and Gynaecology & $19(3.7 \%)$ \\
\hline Ophthalmology & $14(2.7 \%)$ \\
\hline Orthopaedic Surgery & $27(5.3 \%)$ \\
\hline Otorhinolaryngology & $27(5.3 \%)$ \\
\hline Paediatrics & $67(13 \%)$ \\
\hline Pathology & $34(6.6 \%)$ \\
\hline Psychiatry & $50(9.7 \%)$ \\
\hline Radiology & $18(3.5 \%)$ \\
\hline Surgery & $25(4.9 \%)$ \\
\hline Other & $8(1.6 \%)$ \\
\hline Clinical practice & $492(95.7 \%)$ \\
\hline \multicolumn{2}{|l|}{ Level of seniority } \\
\hline Associate consultant & $177(34.4 \%)$ \\
\hline Consultant & $13(2.5 \%)$ \\
\hline Medical officer & $293(57.0 \%)$ \\
\hline Not applicable & $31(6.0 \%)$ \\
\hline Academy Fellow & $284(55.3 \%)$ \\
\hline Academic post & $32(6.2 \%)$ \\
\hline Completely non-medical post & $4(0.8 \%)$ \\
\hline Years in this post & $5.5 \pm 4.5$ \\
\hline Working hours per week & $53.5 \pm 14.8$ \\
\hline \multicolumn{2}{|l|}{ Setting of practice } \\
\hline Government & $49(9.5 \%)$ \\
\hline Hospital Authority & $400(77.8 \%)$ \\
\hline Non-governmental organisation & $2(0.4 \%)$ \\
\hline Private sector (private group/hospital/solo) & $44(8.6 \%)$ \\
\hline University & $18(3.5 \%)$ \\
\hline Not applicable & $1(0.2 \%)$ \\
\hline Providing primary care & $188(36.6 \%)$ \\
\hline
\end{tabular}

Data are shown as No. (\%) or mean \pm standard deviation

\section{Burnout}

As measured by the CBI, the mean personal burnout score was $59.6 \pm 20.5$, work-related burnout score was $57.3 \pm 20.1$, and client-related burnout score was $49.0 \pm 22.3$. Using a CBI subscale cut-off score of $\geq 50$ (moderate and higher), $72.6 \%$ ( $n=373$, 95\% $\mathrm{CI}=68.5 \%-76.4 \%)$ of respondents reported personal burnout; $70.6 \%(\mathrm{n}=363,95 \% \mathrm{CI}=66.4 \%$ $74.5 \%)$ of respondents reported work-related burnout; and $55.4 \%(\mathrm{n}=285,95 \% \mathrm{CI}=51.0 \%-59.7 \%)$
TABLE 3. General well-being, depression, and burnout $(n=5 \mid 4)^{*}$

\begin{tabular}{|c|c|}
\hline \multicolumn{2}{|l|}{ SF-12 (version 1) } \\
\hline Physical component summary & $49.6 \pm 7.8$ \\
\hline Mental component summary & $42.3 \pm 10.6$ \\
\hline PHQ-9 & $6.2 \pm 5.1$ \\
\hline None $(0)$ & $50(9.7 \%)$ \\
\hline Minimal depression (1-4) & $186(36.2 \%)$ \\
\hline Mild depression (5-9) & $168(32.7 \%)$ \\
\hline Moderate depression (10-14) & $69(13.4 \%)$ \\
\hline Moderately severe depression (15-19) & 35 (6.8\%) \\
\hline Severe depression (20-27) & $6(1.2 \%)$ \\
\hline \multicolumn{2}{|l|}{ Copenhagen Burnout Inventory } \\
\hline Personal burnout & $59.6 \pm 20.5$ \\
\hline No/low $(<50)$ & $141(27.4 \%)$ \\
\hline Moderate (50-74) & $238(46.3 \%)$ \\
\hline High (75-99) & $119(23.2 \%)$ \\
\hline Severe (100) & 16 (3.1\%) \\
\hline Work-related burnout & $57.3 \pm 20.1$ \\
\hline No/low $(<50)$ & $151(29.4 \%)$ \\
\hline Moderate $(50-74)$ & $254(49.4 \%)$ \\
\hline High (75-99) & $107(20.8 \%)$ \\
\hline Severe (100) & $2(0.4 \%)$ \\
\hline Client-related burnout & $49.0 \pm 22.3$ \\
\hline No/low $(<50)$ & $229(44.6 \%)$ \\
\hline Moderate (50-74) & $208(40.5 \%)$ \\
\hline High (75-99) & $67(13.0 \%)$ \\
\hline Severe (100) & 10 (1.9\%) \\
\hline
\end{tabular}

Abbreviations: PHQ-9 = Patient Health Questionnaire-9; SF-12 = I2-Item Short Form Survey

Data are shown as No. (\%) or mean \pm standard deviation

of respondents reported client-related burnout (Table 3).

\section{Well-being, depression, and suicidal ideation}

The mean physical component summary score of the 12-Item Short Form Survey was $49.6 \pm 7.8$; the mean mental component summary score of the 12-Item Short Form Survey was $42.3 \pm 10.6$ (Table 3).

As measured by the PHQ-9, the mean depression score was $6.2 \pm 5.1$. However, the prevalence of depression among respondents, defined as a score of $\geq 10$, was $21 \%(n=110)$ [Table 3]. In total, $79 \%(n=404)$ of respondents did not report any suicidal ideation or attempt. The remaining respondents stated that life was "not worth living" or "wished he or she was dead"; some also reported a history of suicidal ideation or attempts. The most commonly cited source of stress in the past year was clinical responsibilities/job demands. 


\section{Health status}

In terms of health conditions, there was a perception among respondents that their health status was "worse" (29\%; $\mathrm{n}=148)$ or "much worse" (3\%; $\mathrm{n}=17$ ) than among other individuals of the same age. The mean duration of sleep each night was $6.2 \pm 1.5$ hours. However, most respondents frequently experienced inadequate sleep when at work; $70 \%(n=361)$ of respondents indicated that this occurred weekly or more often. In terms of personal habits, the prevalences of alcohol drinking, drug addiction, and smoking were low. However, the prevalences of regular physical activity and personal physical assessments were not high (Table 4).

\section{Association of factors for burnout, depression, and suicide}

Logistic regression modelling was performed to investigate bivariate associations of demographic and professional factors with burnout, the presence of depression, or suicide ideation and/or attempts.

The number of working hour(s) per week (odds ratio $[\mathrm{OR}]=1.02 ; 95 \% \mathrm{CI}=1.01-1.04 ; \mathrm{P}=0.001$ ) was positively associated with depression (online supplementary Table 1$)$; having children $(\mathrm{OR}=0.58$; $95 \% \mathrm{CI}=0.36-0.93 ; \mathrm{P}=0.024)$ was negatively associated with suicidal ideation/attempts. Doctors who completed a project-based learning curriculum during undergraduate study were less likely to be depressed or report suicidal ideation/attempts (depression: $\mathrm{OR}=0.60 ; \quad 95 \% \quad \mathrm{CI}=0.39-0.91 ; \quad \mathrm{P}=0.017 ; \quad$ suicidal ideation/attempts: $\mathrm{OR}=0.65 ; \quad 95 \% \quad \mathrm{CI}=0.43-1.00$; $\mathrm{P}=0.049)$ [online supplementary Table 2].

Older age $\quad(\mathrm{OR}=0.97 ; \quad 95 \% \quad \mathrm{CI}=0.94-0.99$; $\mathrm{P}=0.026$ ), possession of a first university degree in medicine or dental surgery $(\mathrm{OR}=0.37$; 95\% $\mathrm{CI}=0.15-0.89 ; \quad \mathrm{P}=0.027)$, and possession of Academy fellowship status (OR=0.61; 95\% $\mathrm{CI}=0.41-0.92 ; \mathrm{P}=0.017)$ were associated with lower likelihood of personal burnout. Engagement in longer working hour(s) per week $(\mathrm{OR}=1.04$; 95\% CI=1.02-1.05; $\mathrm{P}<0.001)$ and working in Hospital Authority clinics $(\mathrm{OR}=1.95 ; \quad 95 \% \quad \mathrm{CI}=1.05-3.62$; $\mathrm{P}=0.034$; compared with working in government clinics) were positively associated with personal burnout (online supplementary Table 3). Marital statuses of single, separated, or divorced $(\mathrm{OR}=1.71$; 95\% $\mathrm{CI}=1.16-2.53 ; \quad \mathrm{P}=0.007)$ and engagement in longer working hour(s) per week $(\mathrm{OR}=1.03$; 95\% $\quad \mathrm{CI}=1.02-1.05 ; \quad \mathrm{P}<0.001) \quad$ were positively associated with work-related burnout (online supplementary Table 4). Conversely, having children ( $\mathrm{OR}=0.66 ; 95 \% \mathrm{CI}=0.44-0.98 ; \mathrm{P}=0.038)$, consultant seniority level $(\mathrm{OR}=0.27 ; 95 \% \mathrm{CI}=0.09-0.88 ; \mathrm{P}=0.029$; compared with associate consultant seniority level), and working in the private sector $(\mathrm{OR}=0.40$; 95\% $\mathrm{CI}=0.17-0.94 ; \mathrm{P}=0.035$; compared with working in government) were negatively associated with
TABLE 4. Sleeping and other personal habits*

\begin{tabular}{|c|c|}
\hline Sleep each night, hours & $6.2 \pm 1.5$ \\
\hline \multicolumn{2}{|c|}{ Feeling inadequate sleep when at work } \\
\hline Daily & $112(21.8 \%)$ \\
\hline Several times per week & $172(33.5 \%)$ \\
\hline Weekly & $77(15.0 \%)$ \\
\hline Several times per month & $75(14.6 \%)$ \\
\hline Monthly & $21(4.1 \%)$ \\
\hline Rarely & $48(9.3 \%)$ \\
\hline Never & $9(1.8 \%)$ \\
\hline \multicolumn{2}{|l|}{ Alcohol drinking } \\
\hline \multicolumn{2}{|c|}{$\begin{array}{l}\text { Frequency of drinking alcoholic beverages } \\
\text { during the past } 12 \text { months }\end{array}$} \\
\hline Less than once per month & $314(61.1 \%)$ \\
\hline Once per month & $52(10.1 \%)$ \\
\hline 2-3 Times per month & $76(14.8 \%)$ \\
\hline Once per week & $37(7.2 \%)$ \\
\hline 2-3 Times per week & $22(4.3 \%)$ \\
\hline 4-6 Times per week & $10(1.9 \%)$ \\
\hline Everyday & $3(0.6 \%)$ \\
\hline \multicolumn{2}{|c|}{$\begin{array}{l}\text { Frequency of consuming } \geq 5 \text { drinks on one } \\
\text { occasion in the past } 12 \text { months }\end{array}$} \\
\hline Never & $392(76.3 \%)$ \\
\hline Less than once per month & $80(15.6 \%)$ \\
\hline Once per month & $23(4.5 \%)$ \\
\hline 2-3 Times per month & $11(2.1 \%)$ \\
\hline Once per week & $6(1.2 \%)$ \\
\hline More than once per week & $2(0.4 \%)$ \\
\hline
\end{tabular}

No. of drink(s) per day during the past month

\begin{tabular}{|cc|}
\hline 0 & $240(46.7 \%)$ \\
\hline 1 & $154(30.0 \%)$ \\
\hline 2 & $78(15.2 \%)$ \\
\hline 3 & $25(4.9 \%)$ \\
\hline 4 & $7(1.4 \%)$ \\
\hline 26 & $5(1.0 \%)$ \\
\hline Drug addiction in the past 12 months & $5(1.0 \%)$ \\
\hline Smoking status & $7(1.4 \%)$ \\
\hline Current smoker & $4(0.8 \%)$ \\
\hline Ex-smoker & $3(0.6 \%)$ \\
\hline Non-smoker & $507(98.6 \%)$
\end{tabular}

Physical activity

Vigorous physical activities, days per week

$\begin{array}{lc}0 & 287(55.8 \%) \\ 1-2 & 185(36.0 \%) \\ 3-4 & 33(6.4 \%) \\ \geq 5 & 9(1.8 \%)\end{array}$

Moderate physical activities, days per week

$0 \quad 209(40.7 \%)$

$1-2 \quad 234(45.5 \%)$

3-4 $61(11.9 \%)$

$\geq 5 \quad 10(1.9 \%)$

Walk for at least 10 minutes at a time, days per week

\begin{tabular}{lc}
0 & $48(9.3 \%)$ \\
$1-2$ & $125(24.3 \%)$ \\
$3-4$ & $103(20.0 \%)$ \\
$\geq 5$ & $238(46.3 \%)$ \\
sical assessment & $388(75.5 \%)$ \\
\hline
\end{tabular}

Data are shown as No. (\%) or mean \pm standard deviation 
work-related burnout. Provision of primary care $(\mathrm{OR}=1.5 ; 95 \% \mathrm{CI}=1.04-2.16 ; \mathrm{P}=0.031)$ was associated with client-related burnout (online supplementary Table 5).

\section{Discussion}

\section{Main findings}

This study attempted to quantify well-being and burnout in young doctors (both resident-in-training, and doctors within 10 years of their specialist registration) throughout Hong Kong; there were three main findings. First, the mean burnout score was high in this group of doctors; mean personal and work-related scores of $\geq 50$ were observed on the CBI. Second, there was a high prevalence of job dissatisfaction (28\%) in this group of doctors. Third, the self-perceived personal well-being and mental health were worse in this group of doctors than in members of the general population with similar ages.

\section{Burnout among doctors in Hong Kong and worldwide}

Burnout is a well-known occupational hazard in people-oriented professions; doctors are at particular risk of burnout because of their frequent engagement in intense personal and emotional contact with patients. Although these therapeutic and service relationships are highly rewarding and engaging, they can also be a source of stress. Burnout among doctors has been recognised as a global crisis ${ }^{20}$; its effects on personal, patient, and institutional levels can be substantial. The expectation to meet job demands can lead to maladaptive practices which will ultimately compromise relationships with patients and colleagues, with long-term consequences on patient care. ${ }^{21}$ Hence, efforts to acknowledge that such a problem exists represents the first step in establishing a systematic strategy to address this crisis.

Although there have been multiple published reports regarding burnout among doctors, territorywide data focusing on junior doctors in Hong Kong are lacking. Siu et $\mathrm{al}^{9}$ conducted a random sample survey of 226 public doctors in 2012; they found that $31.4 \%$ of respondents satisfied the criteria for high burnout. Moreover, young but moderately experienced doctors needing to work shifts were most vulnerable to high burnout. However, the questionnaire used in that study was not comprehensive, the random sampling method did not produce a representative cohort, and only public doctors were invited to the survey. More recently, a more comprehensive survey involving medical graduates of one university in Hong Kong found high prevalences of personal (63.1\%) and 55.9\% (work-related) burnout using the standardised CBI. ${ }^{10}$ The more comprehensive survey represents the most comprehensive and robust study in Hong Kong thus far, but it only included graduates from one university in Hong Kong; it did not include any doctors trained elsewhere.

The present study of young doctors throughout Hong Kong found high mean personal (59.6 \pm 20.5$)$ and work-related $(57.3 \pm 20.1)$ scores on the CBI. The mean client-related score was $49.0 \pm 22.3$, slightly below the score of 50 that constituted the threshold for burnout. These scores were higher than in the previous study performed in Hong Kong by $\mathrm{Ng}$ et $\mathrm{al}^{10}$ which showed mean CBI scores of $57.4 \pm 21.4$ (personal), $48.9 \pm 7.4$ (work-related), and $41.5 \pm 21.8$ (client-related). Moreover, when compared with studies worldwide that used the CBI to measure burnout in doctors, ${ }^{15,16,18,22}$ the levels of burnout in the present study were among the highest. Contributing factors may differ among regional healthcare systems; causes of burnout and well-being in junior doctors may not be consistent worldwide. Our study attempted to identify sources of stress among junior doctors in Hong Kong; the most commonly cited sources were clinical responsibilities/job demands and professional examinations. Additional in-depth studies are necessary to determine how these factors can be modified to alleviate stress in junior doctors.

\section{Health statuses related to burnout risk}

The respondents' general health statuses (in terms of medical conditions) were not substantially worse than the general population, although $32 \%$ of the respondents indicated self-perceived health worse than their peers. The present study also showed that the prevalence of depression was $21 \%$, according to the PHQ-9. This is more than double the prevalence previously reported in Hong Kong (8.4\%). ${ }^{23}$ Despite the high prevalence of depression in the present study, respondents indicated low rates of suicidal ideation/attempts. Although a causal relationship could not be established because of the observational nature of the study, the number of working hours per week and having children were factors that affected risk of depression and suicidal ideation/attempts, respectively. The mean number of hours worked per week was $53.5 \pm 14.8$ hours. Junior doctors who work $>55$ hours per week are reportedly twofold more likely to have frequent health problems $(\mathrm{OR}=2.05$, 95\% $\mathrm{CI}=1.62-2.59 ; \mathrm{P}<0.001)$ and suicidal ideation $(\mathrm{OR}=2.0,95 \% \mathrm{CI}=1.42-2.82 ; \mathrm{P}<0.001) .{ }^{24} \mathrm{~A}$ previous systemic review showed an association between long working hours and a depressive state in other professions in general. ${ }^{25}$ Positive effects of reduced working hours among junior doctors have been found in some studies, ${ }^{26,27}$ but this relationship is not consistently observed. For example, in the United Kingdom, the Working Time Regulations were fully applied to junior doctors beginning in 2009; these 
comprised a limit of 48 hours per week, averaged across a reference period of 26 weeks, with additional minimum rest periods. However, implementation of the Working Time Regulations has not fully resolved the effects of long hours and fatigue. ${ }^{28}$ Furthermore, there are implications for professional training and manpower planning if rigid enforcement of such working hours is performed.

Our study did not find any substantial evidence that young doctors were reliant on alcohol, smoking, or drugs as coping mechanisms. This contrasts with findings from the US, which indicated that high levels of alcohol and substance abuse were associated with burnout among doctors. ${ }^{29}$ It was beyond the scope of the present study to explore other avenues that junior doctors in Hong Kong might use to alleviate their stress levels and burnout. Other health and lifestyle behaviours (eg, exercise levels and personal physical assessments) may be indicative of time constraints related to work or personal obligations; they may also be indicative of self-neglect caused by such constraints and work-related burnout.

\section{Limitations}

This study had several limitations. First, it was a cross-sectional study with voluntary participation, and the results might not be representative of all doctors throughout public and private sectors in Hong Kong. However, to our knowledge, this study performed the most comprehensive survey regarding burnout among doctors in Hong Kong thus far. Second, the study was not designed to avoid selection bias concerning doctors who were more prone to burnout and therefore more interested to participate in such surveys. Third, because the survey did not allow free text entry in the questionnaire responses, more in-depth analysis was not possible in some instances. Fourth, because this was a cross-sectional survey, no causal relationships or risk factors could be established regarding the development of burnout or depression. Fifth, our definition of "young" was based on the 10 years of specialist registration, which included doctors with various levels of experience and responsibilities; thus, the results might not be representative of a specific subset of doctors.

\section{Conclusions}

The present study showed that junior doctors in Hong Kong had a high level of burnout, and there was a high prevalence of depression among the respondents. A substantial proportion of the respondents were dissatisfied with their present job position. Future studies to determine causal factors will allow the development and implementation of specific strategies to address these problems within Hong Kong. The maintenance of well-being in junior doctors is vital for sustaining a healthy medical workforce and long-term patient care.

\section{Author contributions}

Concept or design: All authors.

Acquisition of data: KYH Kwan, LWY Chan, PW Cheng.

Analysis or interpretation of data: KYH Kwan, LWY Chan, PW Cheng.

Drafting of the manuscript: KYH Kwan.

Critical revision of the manuscript for important intellectual content: All authors.

\section{Conflicts of interest}

The authors have no conflicts of interest to disclose.

\section{Acknowledgement}

The authors thank all members of the Young Fellows Chapter of the Hong Kong Academy of Medicine for their active participation in this study; the secretariat and staff of the Hong Kong Academy of Medicine and its Hong Kong Jockey Club Innovative Learning Centre for Medicine for their administrative and information technology support; and the Council of the Hong Kong Academy of Medicine for their active support, encouragement, and funding of the coupons. The authors especially thank Dicken CC Chan for statistical assistance.

\section{Funding/support}

This research received no specific grant from any funding agency in the public, commercial, or not-for-profit sectors.

\section{Ethics approval}

This study was approved by the Institutional Review Board of The University of Hong Kong/Hospital Authority Hong Kong West Cluster (Ref No: UW 19-062).

\section{References}

1. Kane L. Medscape national physician burnout and depression report 2019. Available from: https://www. medscape.com/slideshow/2019-lifestyle-burnoutdepression-6011056. Accessed 2 Dec 2020.

2. Maslach $\mathrm{C}$. What have we learned about burnout and health? Psychol Health 2001;16:607-11.

3. World Health Organization. International Classification of Diseases 11th Revision. QD85 Burnout. Available from: https://icd.who.int/browse11/1-m/en\#/http://id.who.int/ icd/entity/129180281. Accessed 3 Dec 2020.

4. Lin M, Battaglioli N, Melamed M, Mott SE, Chung AS, Robinson DW. High prevalence of burnout among US emergency medicine residents: results from the 2017 National Emergency Medicine Wellness Survey. Ann Emerg Med 2019;74:682-90.

5. BeyondBlue. National Mental Health Survey of Doctors and Medical Students 2019. Available from: https:// www.beyondblue.org.au/docs/default-source/beyondblue-s-strategic-plan-2020-2023/research-projectfiles/bl1132-report---nmhdmss-full-report_web. pdf?sfvrsn=845cb8e9_14. Accessed 3 Dec 2020.

6. Bhugra D, Sauerteig SO, Bland D, et al. A descriptive study of mental health and wellbeing of doctors and medical students in the UK. Int Rev Psychiatry 2019;31:563-8.

7. Gan Y, Jiang H, Li L, et al. Prevalence of burnout and associated factors among general practitioners in Hubei, China: a cross-sectional study. BMC Public Health 
2019;19:1607.

8. Huang EC, Pu C, Huang N, Chou YJ. Resident burnout in Taiwan Hospitals-and its relation to physician felt trust from patients. J Formos Med Assoc 2019;118:1438-49.

9. Siu CF, Yuen SK, Cheung A. Burnout among public doctors in Hong Kong: cross-sectional survey. Hong Kong Med J 2012;18:186-92.

10. Ng AP, Chin WY, Wan EY, Chen J, Lau CS. Prevalence and severity of burnout in Hong Kong doctors up to 20 years post-graduation: a cross-sectional study. BMJ Open 2020;10:e040178.

11. Kristensen TS, Borritz M, Villadsen E, Christensen KB. The Copenhagen Burnout Inventory: a new tool for the assessment of burnout. Work Stress 2005;19:192-207.

12. Rizzo R, Piccinelli M, Mazzi MA, Bellantuono C, Tansella M. The Personal Health Questionnaire: a new screening instrument for detection of ICD-10 depressive disorders in primary care. Psychol Med 2000;30:831-40.

13. Heponiemi T, Kouvonen A, Vänskä J, et al. Health, psychosocial factors and retirement intentions among Finnish physicians. Occup Med (Lond) 2008;58:406-12.

14. Taylor K, Lambert T, Goldacre M. Future career plans of a cohort of senior doctors working in the National Health Service. J R Soc Med 2008;101:182-90.

15. Benson S, Sammour T, Neuhaus SJ, Findlay B, Hill AG. Burnout in Australasian younger fellows. ANZ J Surg 2009;79:590-7.

16. Chou LP, Li CY, Hu SC. Job stress and burnout in hospital employees: comparisons of different medical professions in a regional hospital in Taiwan. BMJ Open 2014;4:e004185.

17. Creedy DK, Sidebotham M, Gamble J, Pallant J, Fenwick J. Prevalence of burnout, depression, anxiety and stress in Australian midwives: a cross-sectional survey. BMC Pregnancy Childbirth 2017;17:13.

18. Wright JG, Khetani N, Stephens D. Burnout among faculty physicians in an academic health science centre. Paediatr
Child Health 2011;16:409-13.

19. Kroenke K, Spitzer RL, Williams JB. The PHQ-9: validity of a brief depression severity measure. J Gen Intern Med 2001;16:606-13.

20. Physician burnout: a global crisis [editorial]. Lancet 2019;394:93.

21. Graham J, Potts HW, Ramirez AJ. Stress and burnout in doctors. Lancet 2002;360:1975-6.

22. Thomas LR, Ripp JA, West CP. Charter on physician wellbeing. JAMA 2018;319:1541-2.

23. Cheng CM, Cheng M. To validate the Chinese version of the $2 \mathrm{Q}$ and PHQ-9 questionnaires in Hong Kong Chinese patients. HK Pract 2007;29:381-90.

24. Petrie K, Crawford J, LaMontagne AD, et al. Working hours, common mental disorder and suicidal ideation among junior doctors in Australia: a cross-sectional survey. BMJ Open 2020;10:e033525.

25. Bannai A, Tamakoshi A. The association between long working hours and health: a systematic review of epidemiological evidence. Scand J Work Environ Health 2014;40:5-18.

26. Kiernan M, Civetta J, Bartus C, Walsh S. 24 Hours on-call and acute fatigue no longer worsen resident mood under the 80-hour work week regulations. Curr Surg 2006;63:23741.

27. Kort KC, Pavone LA, Jensen E, Haque E, Newman N, Kittur D. Resident perceptions of the impact of work-hour restrictions on health care delivery and surgical education: time for transformational change. Surgery 2004;136:861-71.

28. Morrow G, Burford B, Carter M, Illing J. Have restricted working hours reduced junior doctors' experience of fatigue? A focus group and telephone interview study. BMJ Open 2014;4:e004222.

29. Oreskovich MR, Shanafelt T, Dyrbye LN, et al. The prevalence of substance use disorders in American physicians. Am J Addict 2015;24:30-8. 